\title{
PROJEKTOWANIE NOWYCH I MODERNIZACJA ISTNIEJĄCYCH OBIEKTÓW MOSTOWYCH W ASPEKCIE OCHRONY PRZYRODY I KRAJOBRAZU NA PRZYKŁADZIE REALIZACJI W REGIONIE PODLASIA, WARMII I MAZUR
}

\begin{abstract}
W artykule przedstawiono, na wybranych przykładach zrealizowanych obiektów, podstawowe determinanty ochrony krajobrazu i przyrody, jakimi należy się kierować przy opracowaniu dokumentacji projektowej dla nowego, czy też dla remontowanego mostu na terenach krajobrazowo i przyrodniczo cennych. Kryterium uwarunkowań historyczno-krajobrazowych przy projektowaniu i modernizacji starych obiektów jest szczególnie ważne na terenach ,Zielonych Płuc Polski” do jakich można zaliczyć obszar północno-wschodniej Polski. Szczególną uwagę zwrócono na zachowanie formy starych mostów łukowych ze sklepieniem ceglanym. Mosty te znajdują się często w złym stanie technicznym. Przedstawiono dwa rozwiązania konstrukcyjne stosowane przy przebudowie tego typu obiektów: zastosowanie wzmocnienia w postaci stalowych blach karbowanych opartych na żelbetowych przyczółkach oraz wykonanie żelbetowych łuków, oblicowanych cegłą klinkierową, opartych na istniejących podporach, wzmocnionych żelbetowym oczepem. Omówiono na przykładach wybranych obiektów podstawowe uwarunkowania środowiskowe brane pod uwagę przy projektowaniu mostów i przepustów na terenach wiejskich. Zwrócono uwagę na dostosowanie obiektu do otaczającego krajobrazu poprzez zastosowanie odpowiedniej roślinności, zarówno na zabezpieczeniu skarp jak i po obu stronach mostu. Przedstawiono możliwości wykonania przejść dla zwierząt w małych obiektach mostowych i przepustach. Zwrócono uwagę na zagadnienie estetycznego kształtowania konstrukcji mostowych jako dążenie do zachowania formy współgrającej z otoczeniem, szczególnie na obszarze miast, gdzie most jest ważnym punktem widokowym.
\end{abstract}

Słowa kluczowe: mosty, uwarunkowania historyczne, środowisko, zrównoważony rozwój

\footnotetext{
${ }^{1}$ Autor do korespondencji / corresponding author: Agnieszka Jabłońska-Krysiewicz, Politechnika Białostocka, Katedra Konstrukcji Budowlanych, ul. Wiejska 45E, 15-351 Białystok, tel. 8574696 00; a.krysiewicz@pb.edu.pl

${ }^{2}$ Marek Krysiewicz, M-Mosty Marek Krysiewicz, ul. Elewatorska 13/22, 15-620 Białystok; tel. 606675016; m.mosty.krysiewicz@interia.pl
} 


\section{Wprowadzenie}

Pojęcie zrównoważonego rozwoju (ang. sustainability), oznaczające niedestruktywny sposób życia na Ziemi, staje się coraz popularniejszym zagadnieniem nie tylko w krajach tzw. ,starej” Europy, ale i w krajach członkowskich Unii Europejskiej, przyjętych w 2004 roku, w tym również w Polsce. Termin ten został wyjaśniony po raz pierwszy w 1987 roku przez Światową Komisję do spraw Środowiska i Rozwoju, która to zrównoważony rozwój określiła jako dążenie do zaspokajania potrzeb ludzkości w sposób chroniący zasoby środowiska [1]. Bez uwzględnienia w projekcie rozwiązań, które zagwarantują minimalizację negatywnych oddziaływań danej inwestycji na środowisko, nie jest możliwe uzyskanie decyzji o środowiskowych uwarunkowaniach i zgody na realizację przedsięwzięcia, co jest równoznaczne z brakiem uzyskania pozwolenia na budowę [2]. Coraz częściej pod pojęciem „środowisko” kryje się nie tylko szeroko pojęta otaczająca obiekt mostowy przyroda, ale także krajobraz jako całość, a więc także uwarunkowania historyczne miejsca oraz estetyka, rozumiana jako dążenie do harmonijnego organizowania przestrzeni [3]. Kryterium uwarunkowań historyczno-krajobrazowych przy projektowaniu i modernizacji obiektów jest szczególnie ważne na terenach przyrodniczo cennych, do których można zaliczyć obszar północno-wschodniej Polski. Aspekty ochrony zabytków i zachowania form budowli mostowych są szczególnie ważne na terenie Warmii i Mazur, bogatym w liczne dziewiętnastowieczne oraz wzniesione na początku dwudziestego wieku mosty i wiadukty w ciągu dróg kołowych oraz na istniejących liniach kolejowych.

Celem artykułu jest przedstawienie, na wybranych przykładach obiektów podstawowych determinant ochrony krajobrazu i przyrody, jakimi należy się kierować przy opracowaniu dokumentacji projektowej dla nowego, czy też dla remontowanego mostu na terenach krajobrazowo i przyrodniczo cennych.

\section{Uwarunkowania historyczno-krajobrazowe}

Istotnym zagadnieniem, z którym często spotykają się projektanci, jest zachowanie formy architektonicznej obiektu. Dotyczy to również obiektów wzniesionych w dziewiętnastym i na początku dwudziestego wieku, najczęściej łukowych ceglanych i kamiennych. Przebudowa i dostosowanie drogi do wyższej klasy wymusza stosowanie konstrukcji, która jest w stanie przenosić zwiększone obciążenie, a jednocześnie zachowuje pierwotną formę i kształt mostu. W przypadku tego typu obiektów stosowane są miedzy innymi konstrukcje gruntowopowłokowe ze stalowymi łukowymi blachami karbowanymi. Takie rozwiązanie zostało przyjęte w modernizowanym moście w miejscowości Kołodziejki w ciągu drogi krajowej $\mathrm{Nr} 15$, odcinek Lubawa-Ostróda. Istniejący most łukowy wykonany z cegły ceramicznej opierał się na przyczółkach z ciosów kamiennych posadowionych bezpośrednio (rys.1). Pod obiektem, wzdłuż przyczółków, znaj- 
dowały się opaski betonowe. Ściana zwieńczająca łuk ceglany na wlocie i wylocie była wykonana z kamienia łamanego (mur cyklopowy). Na podstawie wniosków z przeprowadzonej inwentaryzacji mostu stwierdzono, że obiekt jest w złym stanie technicznym. Ściana była podwyższana za pomocą muru z bloczków silikatowych. W przyczółkach mostu, opaski betonowe zabezpieczające przed podmywaniem płytko posadowionych przyczółków, oddzieliły się od przyczółków. Na łuku ceglanym na odcinkach po 2,50 m od wlotu i wylotu widać było bardzo silny nalot z mleczka cementowego, świadczący o nieszczelności izolacji łuku ceglanego, której skutkiem były ubytki cegieł (rys. 2). Na wylocie około $20 \mathrm{~cm}$ od lica łuku widoczne było pęknięcie na całym obwodzie łuku. Rozwarcie szczeliny wynosiło około $2 \mathrm{~cm}$. Cegły na końcach łuku były zmurszałe i kruszyły się.

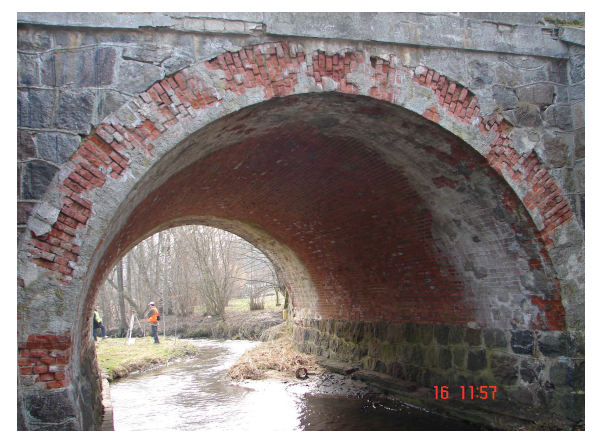

Rys. 1. Most w Kołodziejkach - stan przed przebudową

Fig. 1. The bridge in Kołodziejki - the state before rebuilding

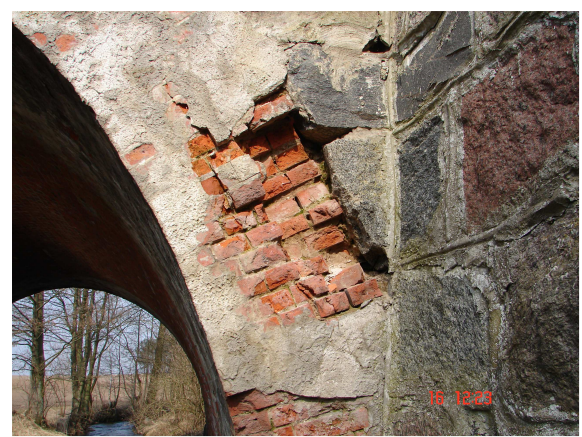

Rys. 2. Most w Kołodziejkach - widoczne ubytki cegieł

Fig. 2. The bridge in Kołodziejki - visible the cavities of bricks

Wysokie koszty naprawy i remontu zadecydowały o rozebraniu obiektu i wykonaniu nowego o konstrukcji łukowej z blach stalowych karbowanych, opartej na żelbetowych przyczółkach (rys. 3).

Innym, często stosowanym rozwiązaniem w modernizowanych ceglanych obiektach łukowych jest zastosowanie sklepienia żelbetowego oblicowanego cegłą. Zaletą takiej konstrukcji jest wzrost nośności mostu, co wiąże się z możliwością dostosowania do wyższej klasy obciążenia. Przykładem obiektu, w którym zastosowano opisane wyżej rozwiązanie jest most przez rzekę Dajnę w miejscowości Pilec w ciągu drogi powiatowej Nr 26551 Szestno - Święta Lipka. Most, zbudowany w 1914 roku, to most ceglany dwuprzęsłowy (rys. 4), w którym przęsła stanowią sklepienia ceglane kołowe oparte na przyczółkach i filarze kamiennym. 


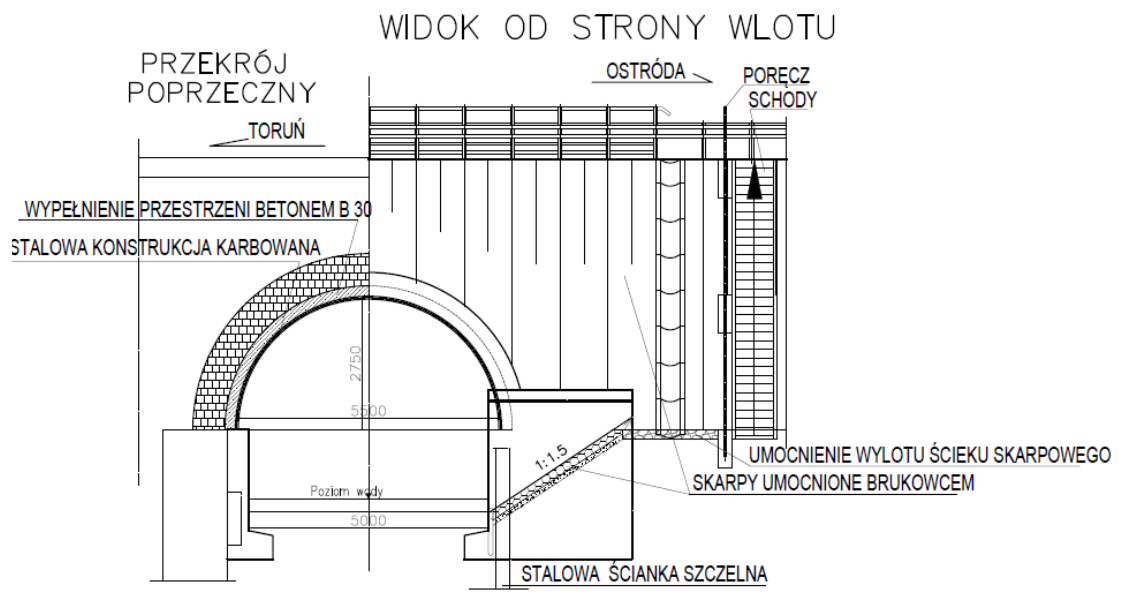

Rys. 3. Most w Kołodziejkach - przekrój poprzeczny zmodernizowanego obiektu

Fig. 3. The bridge in Kołodziejki,- the cross section of rebuilt bridge

$\mathrm{Na}$ podstawie przeprowadzonej inwentaryzacji stwierdzono destrukcję techniczną sklepienia ceglanego. Odnotowano liczne spękania i zacieki, a nieudolne naprawy, wbrew intencjom wykonawców, przyspieszyły tylko proces niszczenia cegieł. Ściany czołowe wykazywały liczne deformacje, na skrzydłach mostu występowały spękania i ubytki spoin oraz miejscami poluzowane kamienie. Stan techniczny oraz konieczność dostosowania do wyższej klasy obciążenia zadecydowały o rozbiórce istniejącego obiektu i budowie nowego mostu, zachowującego formę łukową. Na rysunku 5 pokazano stan mostu po przebudowie.

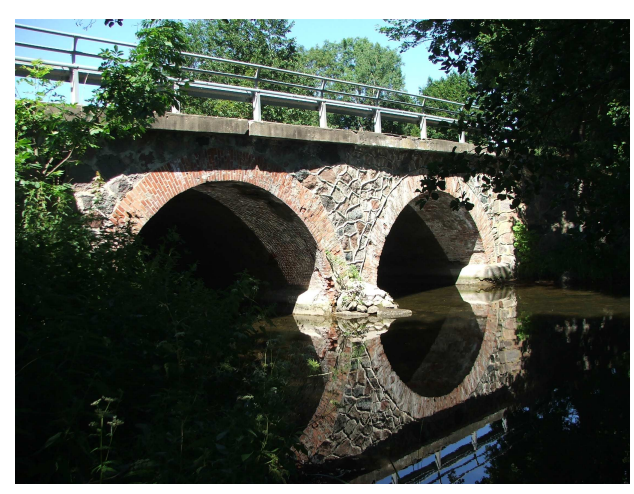

Rys. 4. Most w Pilcu - widok mostu przed przebudową

Fig. 4. The bridge in Pilec -the view of bridge before rebuilding

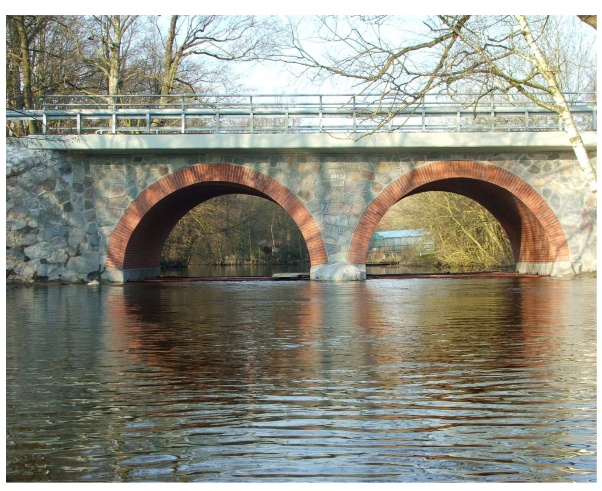

Rys. 5. Most w Pilcu - widok przebudowanego obiektu

Fig. 5. The bridge in Pilec - the view of rebuilt bridge 
Nową konstrukcję nośną zaprojektowano w postaci żelbetowych łuków, oblicowanych cegłą klinkierową, opartych na istniejących podporach, wzmocnionych oczepem żelbetowym. Ściany czołowe wykonano jako żelbetowe obłożone kamieniem, zakończone wspornikami, na których znajdują się chodniki. Na rysunkach 6 i 7 pokazano konstrukcję wsporczą deskowań oraz deskowanie i zbrojenie żelbetowego sklepienia z widoczną oblicówką z cegły klinkierowej.

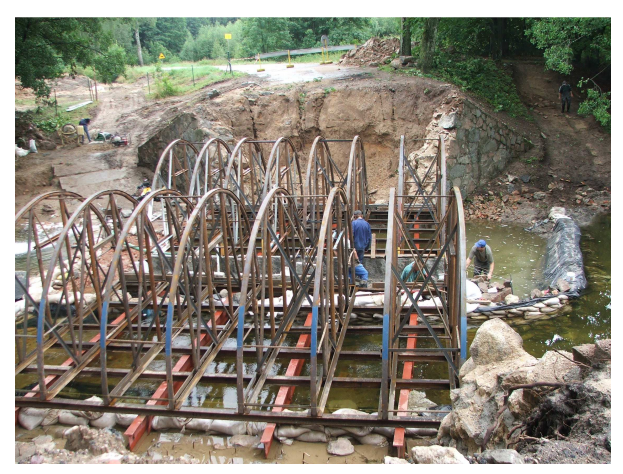

Rys. 6. Most w Pilcu - konstrukcja wsporcza deskowań

Fig. 6. The bridge in Pilec - the supportng structure of formwork

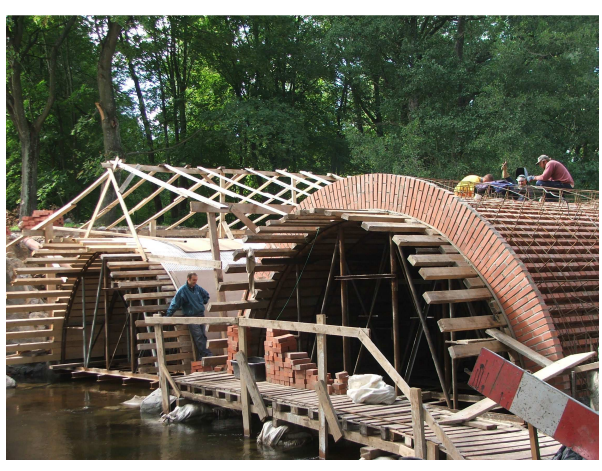

Rys. 7. Most w Pilcu -deskowanie żelbetowych łuków

Fig. 7. The bridge in Pilec - the formwork of reinforced concrete arches

W obszarze zabudowanym obiekty mostowe są ważnymi punktami widokowymi dla pieszych i wolno jadących kierowców. Bardzo dużą rolę odgrywają tutaj detale architektoniczne (np. balustrady - rys 8), zastosowane specjalne materiały oraz tekstura obiektu mostowego, które to są zdecydowanie bardziej zauważalne niż w przypadku obiektów usytuowanych na drogach szybkiego ruchu [4].

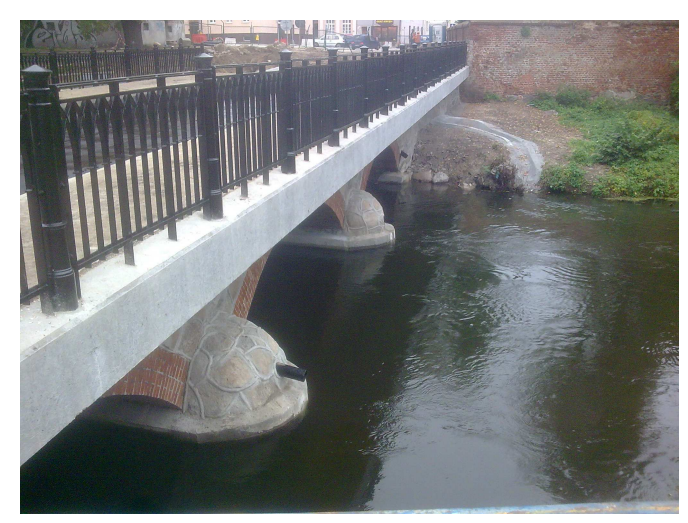

Rys. 8. Most w Lidzbarku Warmińskim - balustrada

Fig.8. The bridge in Lidzbark Warmiński - the balustrade 


\section{Uwarunkowania środowiskowe}

Zasada zrównoważonego rozwoju ściśle związana jest z ochroną środowiska rozumianego jako całość, a więc nie tylko z minimalizacją oddziaływań obiektu na naturalny ekosystem, ale także z ochroną krajobrazu przyrodniczego [5]. Most, zarówno pod względem funkcjonalnym, jak też materiałowym i konstrukcyjnym powinien być dostosowany do otoczenia. Jest to szczególnie ważne na terenach cennych przyrodniczo np. Natura 2000.

W obszarach wiejskich należy dążyć do tego, aby wykorzystać naturalne otoczenie do podkreślenia ciągłości przestrzeni z obu stron mostu [4]. Można to osiągnąć poprzez stosowanie odpowiedniej roślinności, zarówno na zabezpieczenie skarp jak i po obu stronach mostu na odcinkach o odpowiedniej długości tak aby zachować tylko minimalną przerwę na konstrukcję. Takie rozwiązanie zostało przyjęte $\mathrm{w}$ modernizowanym moście w miejscowości Jędrzejki w ciągu drogi powiatowej $\mathrm{nr} 1937 \mathrm{~N}$. Most ten jest usytuowany nad przesmykiem między jeziorami Białe i Stackie. Z uwagi na przylegający do drogi teren, który jest porośnięty lasem oraz wysoką trawą, zaprojektowano obsadzenie skarp roślinnością, aby stanowiły naturalne przedłużenie otaczającego krajobrazu (rys. 9 i 10).

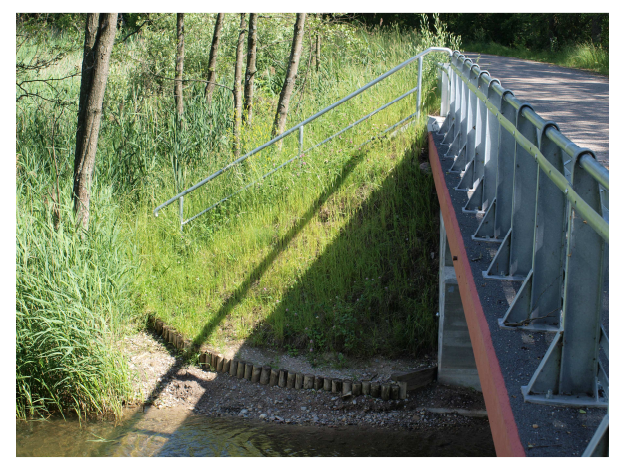

Rys. 9. Most w Jędrzejkach - obsadzenie skarp roślinnością

Fig. 9. The bridge in Jędrzejki - planting vegetation of slopes

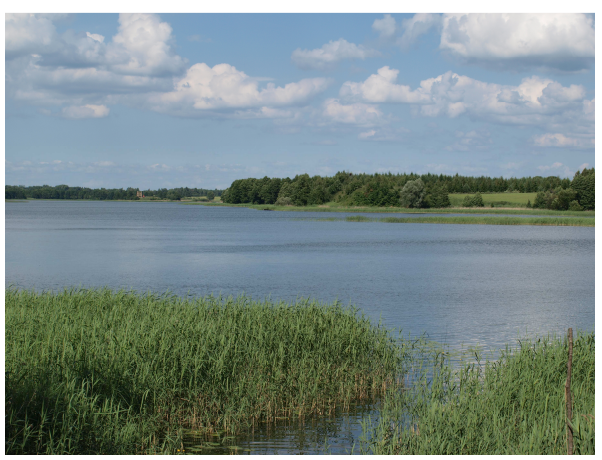

Rys. 10. Most w Jędrzejkach - widok z mostu na jezioro Białe

Fig. 10. The bridge in Jędrzejki - the view form bridge over Białe Lake

Na podstawie Ustawy o Ochronie Środowiska projektant zobligowany jest do uwzględnienia w projektach małych mostów i przepustów przejść dla zwierząt w celu zachowania szlaków migracyjnych lokalnych gatunków fauny w ich naturalnych obszarach siedliskowych. Często stosowanym rozwiązaniem jest pozostawienie opasek betonowych wzdłuż przyczółków mostów szerokości co najmniej 1 metra, umożliwiających przemieszczanie się zwierząt wzdłuż cieków wodnych. Można także łączyć w jednym obiekcie funkcję przepustów z przejściami dla małych zwierząt, projektując obok głównego obiekt dodatkowy. 
Przykładem takiego rozwiązania jest przepust pod ulicą Borsuczą w Białymstoku (rys. 11), który znajduje się na szlaku migracji płazów z obszaru leśnego do położonych po drugiej stronie ulicy stawów i łąk. Konstrukcję głównego przepustu stanowi gruntowo-powłokowa konstrukcja o przekroju kroplistym, natomiast przejście dla zwierząt zaprojektowano z rur stalowych karbowanych o przekroju kołowym.

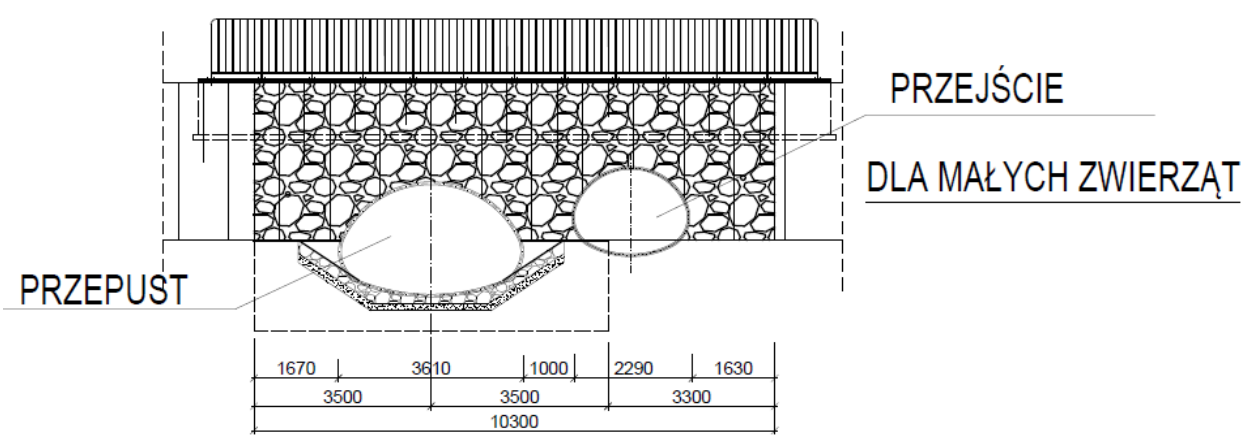

Rys. 11. Przepust z przejściem dla małych zwierząt pod ulicą Borsuczą w Białymstoku

Fig. 11. The culvert with a passage for small animals along Borsucza street in Białystok

\section{Podsumowanie}

W dobie zrównoważonego rozwoju, bez uwzględnienia w projekcie rozwiązań, które zagwarantują minimalizację negatywnego oddziaływania inwestycji na środowisko, nie jest możliwe uzyskanie decyzji o środowiskowych uwarunkowaniach i zgody na realizację przedsięwzięcia, co jest równoważne z brakiem pozwolenia na budowę lub remont. Przy opracowywaniu dokumentacji projektowej mostu coraz ważniejsze stają się również kryteria związane z poszanowaniem krajobrazu jako całości, a więc uwzględnienie uwarunkowań historycznych obiektu i jego otoczenia. Szeroko pojęta estetyka konstrukcji mostu jak i detali architektonicznych coraz częściej jest podstawową przesłanką, którą kierują się wszyscy uczestnicy procesu inwestycyjnego.

Autorzy artykułu pragna podziękować Panu inż. Marcinowi Drabarzowi z firmy DROMO za udostępnienie fotografii z budowy mostu $w$ miejscowości Pilec.

Artykut zostat opracowany w Politechnice Biatostockiej

w ramach pracy statutowej S/WBiIŚ/2/2012, finansowanej ze środków na naukę MNiSW. 


\section{Literatura}

[1] Sarna A.: Zielone drogi - przyszłość dla zrównoważonej Europy. Drogownictwo Nr 5, 2011, s. 176-180.

[2] Leniak-Tomczyk A., Łagoda G.: Środowiskowe uwarunkowania realizacji inwestycji drogowych w Polsce. Drogi i Mosty, Nr 2, 2010, s. 31-52.

[3] Flaga K. i in.: Estetyka konstrukcji mostowych, Wydawnictwo Politechniki Krakowskiej, Kraków 2005.

[4] Jarominiak A.: Obiekty mostowe a środowisko- determinanty estetyki. Inżynieria i Budownictwo, Nr 4, 2011, s. 200-205.

[5] Jabłońska-Krysiewicz A.: Środowiskowe uwarunkowania projektowania i modernizacji obiektów mostowych, W: Energy-saving and ecological materials, installations and technology in construction, Wydaw. Państwowej Szkoły Wyższej im. Papieża Jana Pawła II, Biała Podlaska 2012, s. 132-141.

\section{THE DESIGNING OF NEW BRIDGES AND REBUILDING OF OLD ONES IN TERMS OF NATURE CONSERVATION AND LANDSCAPE PROTECTION BASED ON OBJECTS IN PODLASIE, WARMIA AND MAZURY}

\section{S u m m a r y}

The article presents selected examples of completed facilities basic determinants of landscape protection and nature conservation, which should guide the development of project documentation for the new or the repaired bridge on the areas of landscape and natural value. Criterion conditions historical landscape design and modernization of old bridges is particularly important in the areas of "Green lungs Polish" to which may include the area of north-eastern Polish. Particular attention was paid to the preservation of the old forms of arch bridges with vaulted brick. These bridges are often in poor condition. There were shown two design solutions used in the reconstruction of this type: the use of reinforcement in the form of corrugated steel sheets based on reinforced concrete beachheads and execution of reinforced concrete arches, covered clinker bricks, based on existing supports, reinforced of cup. There were discussed with examples of completed facilities basic environmental considerations taken into account in the design of bridges and culverts on rural areas. Attention was paid to adapt the facility to the surrounding landscape through the use of appropriate vegetation, in protecting of slopes and on both sides of the bridge. There were exemplified feasibility of passages for animals in small bridges and culverts. Attention was paid to the issues of aesthetic shaping of bridge structures as an attempt to be made in harmonizing with the environment, especially in urban areas, where the bridge is an important landmark and viewing point.

Keywords: bridges, historical conditions, environment, sustainable development

DOI: $10.7862 / \mathrm{rb} .2016 .268$

Przestano do redakcji: $30.06 .2016 r$.

Przyjęto do druku: 20.12.2016r. 